\title{
Estimating the duration of an earthquake: Some shaky field observations
}

\author{
ROBERT BUCKHOUT, PHYLLIS FOX, and MARTIN RABINOWITZ \\ Brooklyn College, City University of New York, Brooklyn, New York
}

\begin{abstract}
Data were collected from 246 people on their retrospective recall of the duration of a moderate earthquake in New York state, along with estimates of arousal, alertness, and attention to media. Duration of the quake was pervasively overestimated, with significantly higher overestimates from people in the area where the most intense quake occurred. Correlation of duration estimate with reported arousal was not significant. Responses were interpreted as the result of a desire of respondents to appear as credible observers of a complex episode.
\end{abstract}

At 6:07 a.m., Saturday, October 19, 1985, a minor earthquake struck the general region of Westchester County, New York. Its epicenter was pinpointed near the town of Ardsley, New York (lat. $73^{\circ} 50^{\prime} \mathrm{N}$; long. $40^{\circ} 50^{\prime} \mathrm{W}$ ). The quake, measuring 4.0 on the Richter scale, was felt in widely scattered portions of the Northeast in varying degrees of intensity. According to the LamontDoherty Geological Observatory in Palisades, New York, the quake could be felt for approximately $30 \mathrm{sec}$ at the epicenter.

Within the first few days after the quake, we began to collect data on duration estimates of the length of the quake given by those who were awake during, or those who were awakened by, the event. This was the beginning of the program to study subjective reactions to natural phenomena and to evaluate the social cognitive bases of duration estimates - duration being defined as the interval between two successive events. In this paper, we address the question of whether the lessons learned in laboratory research can be generalized to the real-life task of judging the reliability of time estimates.

Estimation of duration takes place when memory is used either to associate a moment in the past with a moment in the present or to link two past events (Fraisse, 1984). An individual's estimation of the passage of time rarely coincides with the even and mechanical hands of a clock. There is great variability among stimulus modalities, between subjects, and even within a subject at different times. More intense stimuli are judged as lasting longer than less intense stimuli. These findings have been demonstrated for auditory stimulation (Berglund, Berglund, Ekman, \& Frankenhaeuser, 1969), visual stimulation (Goldstone, Lhamon, \& Sechzer, 1978), and vibrotactile stimulation (Ekman, Frankenhaeuser, Berglund, \& Waszak, 1969), suggesting that there is a general relationship between

The authors wish to thank Mary Knoff (Mercy College) and Wes Kayson (Iona College) for their invaluable help in gathering data at their colleges. We further wish to thank staff members of the Lamont-Doherty Geological Observatory who gave us a much-needed education in research on earthquakes. Reprints of this article may be obtained from the senior author of The Center for Responsive Psychology, Brooklyn College, CUNY, Brooklyn, NY 11210. stimulus intensity and duration estimates. Our own experience with eyewitness testimony over the years suggests that precise clock accuracy is the last thing on our minds when we go over the duration of past events. If the time estimate is given at only one occasion, it may be influenced by the form of interrogation, by public knowledge of the event, and by other factors that render it a perceptual $d e$ cision, not a simple estimate.

Fraisse (1964) has formulated a law in which he accounts for the way we make estimates of duration. He states that "any factor which contributes towards an increase or decrease in the number of changes observed, has the effect of lengthening or shortening the apparent duration." The first factor Fraisse addresses is attitude, claiming that we are able to increase the number of changes we perceive by paying attention to the different steps of the task. The more attention we pay to time, the longer it seems.

Ornstein (1969) has proposed a storage size hypothesis, a refinement of Fraisse's work, placing a much greater emphasis on memory. Ornstein states that duration depends on the number of events stored in memory, the number retrieved from memory, and the complexity of these events, with temporal judgment lengthening as these events increase. Falk and Bindra (1954) report that duration is overestimated when a person is forced to attend to the passage of time, but if duration is estimated several times in succession, the amount of overestimation decreases gradually.

We are also influenced by the nature of the task. If a task appears to have more unity, the duration estimate is shorter. Harton (1939) asked subjects to estimate the amount of time it had taken them to learn one fairly difficult mental maze and to learn a more disjointed task (several small mazes of the same type). The actual durations of both were the same, but the estimates were $305 \mathrm{sec}$ for the first task and $444 \mathrm{sec}$ for the second task. We could easily anticipate that the uneven rumblings of the earthquake would lead to similar overestimations.

Another part of Fraisse's law states that when we undergo changes (as a spectator does) rather than create them, the task seems longer. The spectator is not as motivated as the player. When there is slight motivation, we see various steps of the task and are distracted by them; however, 
when we are strongly motivated, we are absorbed by the task, and thus time seems shorter. We simply are not conscious of time when we are satisfied with the present situation. Only fatigue or the actual amount of work accomplished may make us aware of the passage of time (Fraisse, 1964). When we passively perceive, we apprehend changes without arranging them in larger unities because we cannot foresee the stimuli that will occur later. Our subjects, who were passive observers of the earthquake's tremors, would also tend to overestimate its duration.

Quigley, Comb, and O'Leary (1984) studied time estimations among students who were required to participate in an experiment performed at the end of the term, where they had put it off till the last possible moment. They were unmotivated and wished to spend as little time as possible taking part in the experiment. Subjects were told that they would be participating in a brief experiment but would have to wait for the assistant to bring the questionnaires. Control subjects were told the assistant would arrive shortly. Experimental subjects were told by a "frustrated" experimenter that the assistant was overdue. In both cases, the assistant arrived in $5 \mathrm{~min}$. The experimental subjects' estimates of waiting time $(9.94 \mathrm{~min})$ were significantly higher than those of the control group $(7.00 \mathrm{~min})$. This finding supports the hypothesis that the duration of an interval seems longer when time represents a barrier to a desired goal, which, in this situation, was getting the experimental requirement over and done with. Earthquake victims also may be motivated to wish primarily for the experience to end as soon as possible.

The importance of the state of the individual at the time the duration estimate is made was emphasized by Fraisse (1984) who concluded that anxious subjects give longer estimates of waiting time than do less anxious subjects. Falk and Bindra (1954) asked two groups of subjects to estimate a duration of $15 \mathrm{sec}$ several times. Each subject was instructed to press a key and to release it when he/she thought that $15 \mathrm{sec}$ had passed. At the end of that estimated duration, Group 1 heard a bell sound, but Group 2 received a shock. The subjects in Group 2 produced shorter durations, but went on to overestimate the durations they had produced more often than did the subjects in Group 1. Because the waiting time was more intense and anxietyproducing, the elapsed time seemed to be longer than it actually was. Watts and Sharrock (1984) manipulated arousal by exposing spider-phobic subjects and nonphobic subjects to spiders for short intervals. Phobic subjects gave longer time estimates than did nonphobic subjects.

In a retrospective study, Buckhout, Figueroa, and Hoff (1975) staged a crime for an unsuspecting psychology class. A confederate ran into the classroom, verbally challenged the professor, assaulted him, pinned him to the wall, and then ran out of the room. The entire incident took $34 \mathrm{sec}$. The students were asked to write down their estimates of the duration of the incident. The duration was overestimated by a factor of almost $2 \frac{1}{2}$ to 1 , again demonstrating how stress plus complexity leads to overestimation of time. Similar findings have been reported by Johnson and Scott (1976) and Marshall (1966). One common flaw in these experiments was the absence of control groups, which would have allowed the experimenters to compare their results to those obtained from less complex, less arousing forms of the same mock crimes.

Loftus, Schooler, Boone, and Kline (1987) showed two different versions of a videotape of a mock robbery (low stress vs. high stress) to subjects, who were later asked to estimate the duration of the taped episode. All durations were grossly overestimated, but significantly more so in the high-stress condition. The authors further reported a significant trend: Females overestimated duration more than did males. Females also reported higher degrees of arousal than did males. Duration estimates were not related to a measure of general memory accuracy for details of the taped crime. Loftus et al. noted, however, that asking subjects to rate how upset they were produced values that were not correlated with duration estimates.

The tendency to overestimate time has considerable forensic significance, since a witness can enhance his/her credibility by reporting that he/she spent more time in the situation. Who is going to believe, or even listen to, a survivor of an earthquake who slept through or missed most of it? Previous research led us to strongly expect that the subjective duration estimates of the earthquake would be longer than the actual duration of the quake, because the subjects had no choice but to be passive observers of an arousing, nonuniform, and novel situation that they could not control. Guided by the findings that were generated largely from laboratory research, we created a survey research design to test the hypothesis that the amount of overestimation of duration would depend on the experienced quake intensity and that we could expect to find sex differences and some relationship to the degree of emotional arousal.

\section{METHOD}

\section{Subjects}

Data were gathered from a convenience sample of 303 people. We eliminated the data from 40 respondents who reported that they had not been awake during the quake. In all, we had 161 females, 86 males, and 1 subject who did not record his or her gender. Their ages ranged from 17 to 73, with a mean age of 26.86. The respondents, including psychology students from Iona College and Mercy College and individuals from the general population, were questioned individually at a local shopping mall approximately 25 miles from the epicenter.

\section{Procedure and Materials}

Within $48 \mathrm{~h}$ following the earthquake, a pilot questionnaire was administered to a convenience sample of people who had experienced the earthquake, producing a mean duration estimate of $60.2 \mathrm{sec}$. Then the questionnaire was refined to measure (1) duration estimate, (2) level of attention (sleep or state of wakefulness), (3) amount of arousal during the quake, (4) degree of attention paid to media coverage of the quake, (5) subjective first impressions as to cause of the disturbance, (6) exact location, and other demographic measures. The responses within these categories then were converted to numbers ranging from 0 to 7 .

With the help of other colleagues, the questionnaire was administered on the 30th day following the quake. Placement of a respondent in Zone 1 (the area within a 9-mile radius of the epicenter) was based on their presence during the earthquake in the zipcode area defining the epicenter. All other respondents were assigned to Zone 2 (an area up to a 21-mile radius from Zone 1), on the premise that the intensity of the earthquake would be lower as a function of the radial distance from the epicenter. In fact, seismologists advised us that the onset of shock and its dimen- 
sion would produce a longer lasting shockwave of lowered intensity in Zone 2 .

\section{Earthquake Stimulus Characteristics}

Defining the physical intensity and duration of an earthquake is far from precise. It may be safely assumed that intensity diminishes with distance from the epicenter, but the network of seismographic stations on the Eastern seaboard of the United States is thin due to the relative scarcity of seismic events in the region.

No respondents reported the foreshock that occurred at 6:06 p.m., and the time estimates published by the laboratory were based on an analysis (using more refined charts) of the point at which the seismic activity began to fall off on its return to background level. No reliable data were available from the areas we labeled Zone 2, but presumably the duration of the quake was physically longer than at the epicenter, with more vaguely defined starting and stopping points and due to lower intensity and lower amplitude shock waves.

The published duration estimate of $30 \mathrm{sec}$ represents a consensus of expert judgments. Some of the Lamont-Doherty laboratory staff are themselves involved in the collecting of subjective intensity measurements from citizens to supplement the rather impoverished data available from seismographs. They pointed out that subjective experiences of quake intensity can vary a great deal with terrain, structure in which a person resides, bodies of water, and so forth. Furthermore, much of the subjective experience of going through an earthquake is based on the hearing of very loud sounds and the sight or anticipation of falling objects and possible structural damage.

\section{RESULTS AND DISCUSSION}

We further reduced sample data by screening out duration estimates greater than $300 \mathrm{sec}$ (some ran to $5 \mathrm{~min}$ ). Consistent with previous research, the average retrospective quake duration estimates were highly exaggerated (see Table 1). The overall mean duration estimate was $61.12 \mathrm{sec}(S D=65.33)$, with a range of $1-300 \mathrm{sec}$. This represents an exaggeration (ratio score) of 1.53 times the maximum quake duration estimate of $40 \mathrm{sec}$ (Sykes, personal communication, February 18, 1986) and 2.04 times the minimum published time estimate of $30 \mathrm{sec}$ (LamontDoherty Geological Observatory). Computation of ratio scores (Brown, 1985; Hornstein \& Rotter, 1969) is a tactic to permit comparisons, since the duration estimate is simply divided by the actual duration, regardless of time length. Characteristic of the field study, the variances were very high and the median duration estimate was a more impressive $44.6 \mathrm{sec}$. The modal response was $60 \mathrm{sec}$ with other responses clustered at $10,15,20,30,45,90$, and $120 \mathrm{sec}$. This reliance on benchmark responses, previously noted by Loftus et al. (1987) (comprising 76.8\% of all responses in the present study), suggests guessing by respondents to fulfill the social obligation to account for their memory of the earthquake episode. This tendency also contributes to high variances and a certain degree of sloppiness in field-generated data.

A $t$ test of the difference in mean perceived duration estimates between respondents located in the immediate epicenter area (Zone 1) and those located in Zone 2 showed that respondents in Zone 1 gave significantly higher duration estimates $[t(244)=1.959, p<.05]$ than did respondents in Zone 2 . This finding is compatible with Ornstein's (1969) storage size hypothesis. The quake waves, which were of greater intensity in Zone 1 , might have had longer decay times in sensory storage than did the weaker waves of Zone 2, thereby contributing to the longer time estimates. Another reason for the highly exaggerated duration estimates might have been the method used to collect the data. It has been shown that verbal estimates of duration (which we used in our survey) tend to be longer and more inaccurate than do estimates based on other methods, such as the method of reproduction (Brown, 1985; Fraisse, 1964). As the data show in Table 1, there were nonsignificant trends for female respondents to give higher duration and ratio scores. Analysis of reported arousal during the earthquake showed that female respondents were significantly more aroused than were males $(p<.006)$. In Table 2 , the ratio data were rearranged into three categories: overestimates, correct, and underestimates. With the data grouped by respondent sex, a chi test showed that females tended to overestimate duration more frequently than did men $(p<.01)$. However, the correlation between reported arousal level and duration estimate was not significant $(r=-.06)$.

In Table 3, mean duration estimates from other categories on the questionnaire are presented with notes on the results of separate ANOVAs performed on each item and the percent of respondents falling into each subcategory of each variable. Note that even those respondents who were awake during the earthquake did not differ in their duration estimates from those who were asleep at the start. ANOVAs on initial interpretations of the quake, whether people consulted other people or the media, and the degree of media attention showed nonsignificant effects on duration estimates. Only the education level of the respondent had a significant effect on mean duration estimate, with the more highly educated tending to underestimate the duration of the quake $[F(2,237)=4.02$, $p<.02]$. This linear relationship resulted in a significant negative correlation between education and duration estimate $(r=-.18, p<.05)$. Finally, note that a count of the overestimators and underestimators (the $\mathrm{O} / \mathrm{U}$ index) in each category shows uniformly that most respondents overestimated the duration of the quake (the exception being the highly educated respondents).

Table 1

Mean Duration Estimates and Arousal Levels as Functions of Quake Intensity and Respondent Gender

\begin{tabular}{lcccc}
\hline Condition & $n$ & $\begin{array}{c}\text { Mean Duration } \\
\text { Estimate } \\
(1-300 \mathrm{sec})\end{array}$ & $\begin{array}{c}\text { Mear } \\
\text { Arousal } \\
(0-7)\end{array}$ & $\begin{array}{c}\text { Overestimate } \\
\text { Ratio } \\
\text { (Est: 30 sec) }\end{array}$ \\
Zone 1 & 20 & 62.95 & 2.05 & 2.10 \\
Zone 2 & 65 & 50.98 & 2.06 & 1.70 \\
All Males & 85 & 53.80 & 2.06 & 1.79 \\
& \multicolumn{5}{c}{ Males } \\
Zone 1 & 57 & 76.72 & 3.11 & \\
Zone 2 & 103 & 59.06 & 2.65 & 1.97 \\
All Females & 160 & 65.35 & $2.81 \dagger$ & 2.18 \\
& \multicolumn{5}{c}{ All Subjects } \\
Zone 1 & 77 & $73.14 \ddagger$ & 2.83 & \\
Zone 2 & 169 & 55.64 & 2.43 & 1.85 \\
Combined & 246 & 61.12 & 2.55 & 2.04 \\
\hline
\end{tabular}

Note-Zone 1 = high intensity; Zone 2 = low intensity. *Correlation of duration estimate with arousal $(r=-.06)$. † Significantly higher than males $(p<.007)$. $\ddagger$ Significantly higher than in Zone $2(p<.05)$. 
Table 2

Percentage of Underestimates, Overestimates, and Correct Estimates of Earthquake Duration

\begin{tabular}{lccc}
\hline \multicolumn{1}{c}{ Subjects } & Underestimates & Correct & Overestimates \\
\hline Males & 41.6 & 17.6 & 41.2 \\
Females & 24.4 & 16.3 & 59.4 \\
Overall Sample & 30.2 & 16.7 & 53.1 \\
\hline
\end{tabular}

Note $-\chi^{2}(5, N=245)=8.72 ; p<.01$.

Is this perception as we might classically define it? We doubt it. The reliance of most respondents on ballpark estimates argues against it. An earthquake begins without warning, without giving us an opportunity to reflect on its beginning or its end. Brown (1985) found in his extended studies that retrospective time estimates increased in absolute terms as a function of complexity and divided attention in a task. In Brown's words, "the more that one becomes distracted from processing temporal cues, the more inaccurate one's timing becomes.' Retrospective time judgments involve the use of real (probably degraded) temporal information on a more incidental basis.

Processing temporal information is not the only thing involved in retrospective time estimation. Questionnaires themselves carry social demands that may alert the respondent to give balanced, plausible responses about their role

Table 3

Breakdown of Earthquake Duration Estimates and Key Questionnaire Items

\begin{tabular}{cccc}
\hline & & $M$ Dur. & $\mathrm{O} / \mathrm{U}$ \\
Level & Percent & Est.* & Index \\
\hline
\end{tabular}

\begin{tabular}{lccc}
\multicolumn{4}{c}{ Attention Level at Start of Quake } \\
Asleep & 53.5 & 61.80 & + \\
Awake & 46.5 & 60.35 & + \\
& Interpretation of Episode & \\
Bad Dream & 7.7 & 56.32 & 0 \\
Loud Noise & 34.2 & 58.90 & + \\
Earthquake & 27.7 & 66.89 & + \\
Other & 30.5 & 71.92 & + \\
& First Information Source Consulted & \\
People & 35.5 & 63.87 & + \\
Media & 64.5 & 59.64 & + \\
& & \\
None & Degree of Media & Attention & \\
Very Little & 3.3 & 46.56 & - \\
Some & 8.3 & 82.74 & + \\
Everything & 47.8 & 54.42 & + \\
& 27.8 & 67.91 & + \\
High School or Less & 11.5 & 85.46 & + \\
Some College & 70.8 & 58.96 & + \\
Post-College & 17.7 & 44.09 & - \\
& Age & & \\
17-19 years & 26.5 & 51.12 & + \\
20-26 years & 33.5 & 63.40 & + \\
$27-73$ years & 40.0 & 72.56 & + \\
\hline
\end{tabular}

Note $-\mathrm{O} / \mathrm{U}$ index is the ratio of overestimators to underestimators, where $+=$ more overestimators than underestimators, $-=$ more underestimators than overestimators, and $0=$ an equal distribution of overestimators and underestimators. *Mean duration estimate. as observers of a highly significant episode, whether or not there is a basis for such responses. Given the low mean arousal scores reported, it might be that respondents wanted to appear to have been calm, thus choosing to avoid such labels as "extremely upset." In fact, $\mathbf{7 7 . 8 \%}$ of our respondents described themselves using only the first four descriptors on the 8-point arousal scale (calm to uneasy). Loftus et al. (1987) reported that the analysis of their subject arousal data was confined to the first two levels of the arousal scale used in their design. If a person is trying to justify his/her knowledge of the earthquake by retrospectively overestimating the time he/she spent in it, this person probably would also retrospectively downgrade his/her level of anxiety or arousal. Research with eyewitnesses to crimes (Buckhout, 1974; Loftus, 1977) has provided ample evidence of a witness's tendency to fill in descriptions, dates, locations, and duration estimates. The present experimental results appear to be very consistent with that work.

\section{REFERENCES}

Berglund, B., Berglund, U., Ekman, G., \& Frankenhaeuser, M. (1969). The influence of auditory intensity of apparent duration. Scandinavian Journal of Psychology, 10, 21-26.

Brown, S. W. (1985). Time perception and attention: The effects of prospective versus retrospective paradigms and task demands on perceived duration. Perception \& Psychophysics, 38, 115-124.

BuckHout, R. (1974). Eyewitness testimony. Scientific American, 231, 23-31.

Buckhout, R., FigueroA, D., \& HoFf, E. (1975). Eyewitness identification: Effects of suggestion and bias in identification from photographs. Bulletin of the Psychonomic Society, 6, 71-74.

Ekman, G., Frankenhaeuser, M., Berglund, B., \& Waszak, M. (1969). Apparent duration as a function of intensity of vibrotactile stimulation. Perceptual \& Motor Skills, 28, 151-156.

FALK, J. L., \& BindRA, D. (1954). Judgment of time as a function of serial position and stress. Journal of Experimental Psychology, 47, 279-284.

Fraisse, P. (1964). The psychology of time. London: Eyre \& Spottiswoode.

Fraisse, P. (1984). Perception and estimation of time. Annual Review of Psychology, 35, 1-36.

Goldstone, S., Lhamon, W. T., \& Sechzer, J. (1978). Light intensity and judged duration. Bulletin of the Psychonomic Society, 12, 83-84.

HARTON, J. J. (1939). The influence of the degree of unity of organization on the estimation of time. Journal of General Psychology, 21, 25-49.

Hornstein, A. D., \& RotTER, G. S. (1969). Research methodology in temporal perception. Journal of Experimental Psychology, 79, 561-564.

JoHNSON, C., \& SCOTT, B. (1976). Eyewitness testimony and suspect identification as a function of arousal, sex of witness, and scheduling of interrogation. Paper presented at the meeting of the American Psychological Association, Washington, DC.

LoFTus, E. F. (1977). Eyewitness testimony. Cambridge, MA: Harvard University Press.

LofTus, E. F., SCHOOLER, J. W., BoONe, S. M., \& Kline, D. (1987). Time went by so slowly: Overestimation of event duration by males and females. Journal of Applied Cognitive Psychology, 1, 3-15.

Marshall, J. (1966). Law and psychology in conflict. New York: Bobbs-Merrill.

OrNSTEIN, R. E. (1969). On the experience of time. Harmondsworth, England: Penguin Books.

Quigley, J. J., Combs, A. L., \& O'Leary, N. (1984). Sensed duration of time: Influence of time as a barrier. Perceptual \& Motor Skills, 58, 72-74.

WatTs, F. N., \& Sharrock, R. (1984). Fear and time estimation. Perceptual \& Motor Skills, 58, 597-598.

(Manuscript received December 3, 1988.) 